\title{
Resource Use and Morphology of Two Sympatric Japalura Lizards (Iguania: Agamidae)
}

\author{
ChI-Yun KuO, ${ }^{1}$ YaO-Sung Lin, ${ }^{1,2}$ AND Y. KiRK $\operatorname{Lin}^{1,2,3}$ \\ ${ }^{1}$ Institute of Ecology and Evolutionary Biology, National Taiwan University, Taipei 106, Taiwan, Republic of China \\ ${ }^{2}$ Department of Life Sciences, National Taiwan University, Taipei 106, Taiwan, Republic of China
}

\begin{abstract}
Aвstract.-We investigated the underlying mechanism of coexistence of two sympatric Japalura lizards (Japalura swinhonis and Japalura polygonata xanthostoma). We examined the differences in resource use along three resource dimensions: time, space, and diet. Specifically we tested two ecomorphological hypotheses. Correspondence exists between: perch habitat and limb morphology, and diet and head morphology. The species with shorter forelimbs would perch on narrower surface. The species with larger heads would consume larger or tougher prey. The results showed that the two species did not divide resources by temporal partitioning. Spatially, the two species used similar macrohabitats. However, female $J$. swinhonis, perching lower and on narrower surfaces, differed from other groups in perch habitats. However, male J. swinhonis and J. p. xanthostoma, despite size and shape differences, were similar in perch habitat. In addition, high diet overlap was detected both intra- and interspecifically despite the presence of significant differences in head sizes. In conclusion, male J. swinhonis and J. p. xanthostoma used largely overlapping resources and therefore, might be potential competitors if resources are limited. We suggest that there was a trade-off between fighting ability and maneuverability because of morphological differences that allowed the coexistence of the two species. Although male J. swinhonis, being larger, may have better fighting ability, J. p. xanthostoma could maneuver around tree trunks and branches to search for prey and avoid fighting more easily.
\end{abstract}

Resources constitute key dimensions in a biological niche for their importance in supporting organisms' survival and reproduction (Hutchinson, 1957). Assuming limited resources, effectiveness in utilizing resources imposes a strong selective pressure on organisms. The target of selection can be any phenotypic trait directly or indirectly related to the acquisition or processing of resources. In many circumstances, however, it is the morphology of body parts that is the target of selection. For example, in the classic study of Darwin's Finches, researchers have found that species with different bill shapes effectively use seeds of different size and hardness (Schluter and Grant, 1984; Grant, 1986). Similarly, feeding structures of Three-Spined Sticklebacks in postglacial lakes of Alaska have diverged between populations that feed in different microhabitats (Walker, 1997).

The correspondence between resource use and morphology has also been intensively studied in squamates. Several studies have demonstrated correspondence between head morphology and prey size or type: species with large heads consume large prey (Forsman and Lindell, 1993; Preest, 1994; Verwaijen et al.,

\footnotetext{
${ }^{3}$ Corresponding Author. E-mail: kirklin@ntu. edu.tw
}

2002; Vincent et al., 2004). Other studies have found correspondence between body shape/ limb morphology and habitat type occupied. For example, a study on Tasmania Niveoscincus lizards showed that species occupying open microhabitats were larger and had longer limbs than those inhabiting closed microhabitats (Melville and Swain, 2000). Studies on Tropidurus and Phrynosomatid lizards have also discovered that species occupying open and closed microhabitats differed significantly in snout-vent lengths and the ratio of tibia to femur (Kohlsdorf et al., 2001; Herrel et al., 2002). However, a series of studies on the genus Anolis, whose members are exclusively arboreal or semiarboreal, demonstrated that species using wide perches have relatively longer limbs and sprint faster but have poorer maneuverability, than species using narrow perches (Williams, 1972; Losos, 1990; Irschick and Losos, 1998; Beuttel and Losos, 1999).

Closely related species can coexist via resource partitioning, which can be attributed to differences in morphology, as demonstrated in Caribbean Anolis lizards (reviewed in Losos, 1994). However, most studies seeking to establish a correspondence between habitat use and morphology in other lizard clades, although successfully demonstrating adaptation, bear little relevance to the underlying mechanisms of species coexistence because the clade mem- 
bers included in the analysis inhabited distinct macrohabitats and, therefore, are not sympatric (e.g., Melville and Swain 2000; Herrel et al. 2002; Schulte et al., 2004). Here, we report a study that investigated the mechanisms that might contribute to the local coexistence of two closely related Japalura species.

Lizards in the genus Japalura (Family Agamidae) are widely distributed over east and Southeast Asia; however, ecological information remains limited (Wei and Lin, 1981; Lin and Lu, 1982; Lin and Cheng, 1986; Jian, 1990) and anecdotal (Shan, 2001). Swinhoe's Tree Lizard (Japalura swinhonis) and Yellow-Mouthed Tree Lizard (Japalura polygonata xanthostoma) are the most common Japalura lizards on Taiwan. The endemic J. swinhonis is the largest Japalura in Taiwan, and can reach $31 \mathrm{~cm}$ in total length (Shan, 2001). It is found in various habitats with sufficient sunlight below 1,500 $\mathrm{m}$ throughout the island, including wooded areas and habitats with intensive human activities. Individual lizards often perch on tree trunks and occasionally the ground or branches. The closely related J. p. xanthostoma is an endemic subspecies in Taiwan. The species is morphologically similar to $J$. swinhonis and occupies similar habitats (Shan, 2001). Yet, its distribution is confined to northern Taiwan where the two species often co-occur in the same habitats.

During preliminary field observations, we suspected that, despite general similarity, the differences in certain aspects of morphology might allow resource partitioning between the two species and, thus, local coexistence. The purpose of this study was to investigate the mechanisms that allow local coexistence of the two species. We examined whether the two species use different fractions of the available resources in a location of sympatry and whether morphological differences correspond to differential resource use between the two species. Specifically, we tested two hypotheses. First, the two species partition resources in one or both resource dimensions: perch habitat and diet. Second, correspondence exists between limb morphology and perch habitat and head morphology and diet. The species with shorter forelimbs would perch on narrower surface. The species with larger heads would consume larger or tougher prey.

\section{Materials And Methods}

Study species._Japalura swinhonis are sexually dimorphic. Males have a bright yellow stripe running along each side of body, large dewlaps, and prominent heads. Females are relatively smooth in head shape and have no lateral stripes. The yellow oral cavity is a unique feature of J. p. xanthostoma (Shan, 2001). The species is also sexually dimorphic. Males have yellow lateral stripes, conspicuous dewlaps, and crimson color on the throat. Females are relatively greenish, and some individuals have faint yellow stripes. The crimson color on the throat distinguishes male J. $p$. xanthostoma from conspecific females and J. swinhonis. Body coloration and size distinguish females of the two species from each other.

Study site.-The study site was a wooded hill bordered by the Taipei City Zoo $\left(24^{\circ} 24^{\prime} \mathrm{N}\right.$ and $121^{\circ} 21^{\prime} \mathrm{E}$ ). The canopy was fairly open, creating patches of light and shade in the understory vegetation, which was dense and structurally complex with various fern, grass, and shrub species. Other than J. swinhonis and J. p. xanthostoma, five other lizard species occurred at the study site, Kuhne's Grass Lizard (Takydromus kuehnei), Formosan Grass Lizard (Takydromus formosanus), Taiwan Smooth Skink (Scincella formosensis), Indian Forest Skink (Sphenomorphus indicus), and Elegant Skink (Eumeces elegans). The grass lizards, smaller in size than Japalura, were rare and occurred on understory vegetation. The skink species occurred on the ground. Japalura swinhonis and J. p. xanthostoma were the most common lizards at the study site and were the only species that used vertical surfaces (C-YK, pers. obs.). Because other lizard species either had far lower abundance than Japalura at the study site or used different habitats, they were unlikely to be in direct competition with Japalura spp.

Daily activity patterns and perch habitat.-Data on daily activity patterns and perch habitat were collected on 12 sunny days during June and July 2004 and on 27 sunny days from March through June 2005. In 2004, one observer walked slowly along a deserted hiking trail winding through the woods once per hour from 0700-1800 h, looking for lizards on either side of the trail. The number of lizards spotted in every hourly interval was recorded to establish the daily activity patterns of the two species. We used Chi-square test of homogeneity to analyze the difference of patterns between the two species.

In 2005, two observers walked slowly along the same hiking trail once in the morning between 0900 and $1200 \mathrm{~h}$ and again in the afternoon between 1400 and $1700 \mathrm{~h}$, searching systematically for lizards. Lizards were caught either by hand or noose. We recorded the species, sex, initial perch height and diameter, and morphometric measurements (see below) for each lizard captured. Perch height was measured to the nearest $1 \mathrm{~cm}$; perch diameter to the nearest $1 \mathrm{~mm}$. Every captured lizard was given a unique number on its back with water- 
TABLE 1. Perch habitats, including perch height, perch diameter, and size and shape variables of Japalura swinhoni and Japalura polygonata xanthostoma. All size and shape variables and perch diameter are in millimeters. Perch height is in $\mathrm{cm}$. Values are mean $\pm 1 \mathrm{SD}$. Sample sizes are given in parentheses.

\begin{tabular}{|c|c|c|c|c|}
\hline & \multicolumn{2}{|c|}{ J. swinhonis } & \multicolumn{2}{|c|}{ J. p. xanthostoma } \\
\hline & Males & Females & Males & Females \\
\hline \multicolumn{5}{|l|}{ Perch habitat } \\
\hline Perch height & $\begin{array}{c}145.5 \pm 81.4 \\
(184)\end{array}$ & $\begin{array}{c}73.4 \pm 75.7 \\
(72)\end{array}$ & $\begin{array}{c}124.7 \pm 85.3 \\
(68)\end{array}$ & $\begin{array}{c}122.7 \pm 85.3 \\
(27)\end{array}$ \\
\hline Perch diameter & $\begin{array}{c}78.8 \pm 77.5 \\
(118)\end{array}$ & $\begin{array}{c}71.1 \pm 108.7 \\
(65)\end{array}$ & $\begin{array}{c}113.3 \pm 115.5 \\
(68)\end{array}$ & $\begin{array}{c}118.4 \pm 89.3 \\
(27)\end{array}$ \\
\hline \multicolumn{5}{|l|}{ Size variables } \\
\hline HW & $17.2 \pm 2.00$ & $12.7 \pm 0.90$ & $11.7 \pm 0.98$ & $11.3 \pm 1.02$ \\
\hline $\mathrm{HL}$ & $25.8 \pm 2.26$ & $20.5 \pm 1.37$ & $18.8 \pm 1.34$ & $18.2 \pm 1.51$ \\
\hline FLIMB & $24.4 \pm 1.30$ & $20.8 \pm 1.22$ & $19.1 \pm 1.50$ & $18.3 \pm 0.82$ \\
\hline HLIMB & $\begin{array}{c}37.8 \pm 2.07 \\
(47)\end{array}$ & $\begin{array}{c}32.4 \pm 2.12 \\
(40)\end{array}$ & $\begin{array}{c}27.0 \pm 2.22 \\
(21)\end{array}$ & $\begin{array}{c}26.3 \pm 1.86 \\
(14)\end{array}$ \\
\hline \multicolumn{5}{|l|}{ Shape variables } \\
\hline SIZE & $29.03 \pm 1.61$ & $24.00 \pm 1.25$ & $21.50 \pm 1.28$ & $21.00 \pm 1.11$ \\
\hline $\mathrm{HW} / \mathrm{SIZE}$ & $0.59 \pm 0.05$ & $0.53 \pm 0.02$ & $0.54 \pm 0.03$ & $0.54 \pm 0.03$ \\
\hline $\mathrm{HL} / \mathrm{SIZE}$ & $0.89 \pm 0.05$ & $0.85 \pm 0.04$ & $0.87 \pm 0.04$ & $0.87 \pm 0.04$ \\
\hline FLIMB/SIZE & $0.84 \pm 0.04$ & $0.87 \pm 0.05$ & $0.89 \pm 0.03$ & $0.87 \pm 0.04$ \\
\hline LIMB/SIZE & $\begin{array}{c}1.30 \pm 0.05 \\
(47)\end{array}$ & $\begin{array}{c}1.35 \pm 0.05 \\
(40)\end{array}$ & $\begin{array}{c}1.25 \pm 0.06 \\
(21)\end{array}$ & $\begin{array}{c}1.25 \pm 0.04 \\
(14)\end{array}$ \\
\hline
\end{tabular}

insoluble paint as a temporary mark and toeclipped in a unique combination as a permanent mark. Lizards were released at the location of capture immediately after processing. We applied two-way analyses of variance (ANOVA) on perch height and perch diameter, with species and sex as fixed factors, and used least significant difference tests (LSD) for post hoc pairwise comparisons when ANOVA yielded significant results.

Morphometric analysis.-We measured the following eight size variables: snout-vent length (SVL, measured from the cloacal opening to the tip of snout), left forelimb length (FLIMB, measured from the point where upper arm joins the body to wrist), left hind-limb length (HLIMB, measured from the point where upper leg joins the body to ankle), length of the longest finger and toe of left limbs (FIN and TOE, claws were not included in the measurement), head length $(\mathrm{HL}$, measured from lower jaw to the tip of snout), head width (HW, the greatest width of the head, which was measured as the distance between the joints of upper and lower jaw on both sides), and tail length (TAIL, measured from cloacal opening to the tip of the tail). SVL was not used in morphometric analysis because it included head length. Instead, we obtained body length (BL) from the difference between SVL and HL. All size variables were measured to the nearest $0.01 \mathrm{~mm}$ using a digital caliper, except TAIL, which was measured to the nearest $1 \mathrm{~mm}$ with a digital caliper.
We used Mosimann's (1970) method as described in Butler and Losos (2002) to generate shape variables for each individual. We defined general size (hereafter SIZE) as the geometric mean of the eight morphological variables: FLIMB, HLIMB, FIN, TOE, HL, HW, TAIL, and BL. Shape variables were produced by dividing a morphological variable by SIZE. We only report HW and HL, and FLIMB and HLIMB in the Results (Table 1) because of their well-demonstrated relevance in diet and perch habitat, respectively (Irschick and Losos, 1998; Beuttel and Losos, 1999; Verwaijen et al., 2002). We applied two-way ANOVAs on size and shape variables, with species and sex as fixed factors and used LSD for post hoc pairwise comparisons. All morphological variables were natural $\log (\ln )$ transformed prior to statistical analyses.

Diet.-Stomach contents were obtained on 12 days from July through October 2005. Upon capture, lizards were injected orally with 5$10 \mathrm{ml}$ of $0.9 \%$ saline using a $5-\mathrm{ml}$ syringe to flush the stomach. Stomach contents were preserved in $70 \%$ alcohol. Insects were identified to order and other food to class with the aid of reference collections of arthropods in the study area. Proportion of stomachs containing a given prey taxon (occurrence frequency) was calculated as the number of stomachs containing that particular prey taxon divided by the total number of stomachs. Prey taxa whose occurrence frequencies $>0.05$ in at least one speciessex group were included in further analyses. 


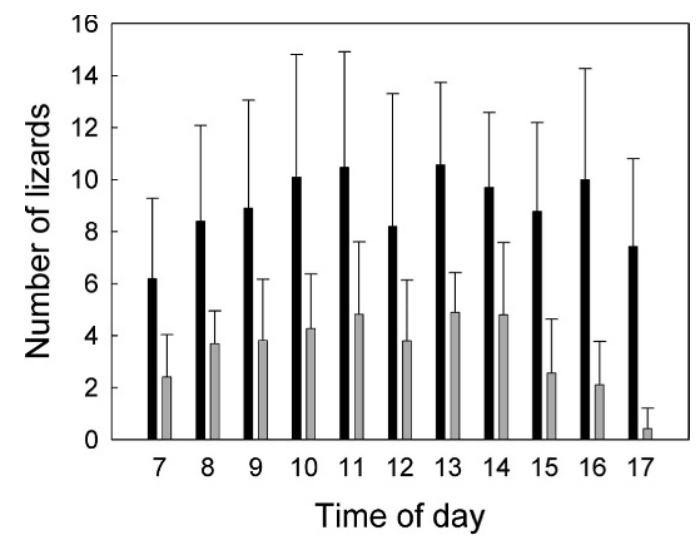

FIG. 1. Mean number of Japalura swinhonis (black bars) and Japalura polygonata xanthostoma (gray bars) sighted in each hourly interval from 0700-1800 h. Error bars give standard deviations.

For each stomach, wet mass of every prey taxon was measured to the nearest $0.001 \mathrm{~g}$. To prevent biases caused by the 0.001-g limit of the instrument, stomachs containing prey taxa that weighed $<0.001 \mathrm{~g}$ were excluded from further analysis if total mass of stomach contents was less than $0.02 \mathrm{~g}$. This procedure guaranteed that any prey weighing $<0.001 \mathrm{~g}$ would occupy no more than $5 \%$ of the total mass. Percent mass of every prey taxon was then obtained on a stomach-by-stomach basis. Afterward, mean percent mass of every prey taxon was calculated.

We calculated the index of relative importance (IRI) using the method described by Bjorndal et al. (1997) with volume replaced by mass:

$$
I R I=100\left(F_{i} W_{i}\right) / \sum_{l}^{n}\left(F_{i} W_{i}\right)
$$

where $F$ denotes occurrence frequency, $W$ mean percent mass, and $n$ the number of prey taxa.

We compared the occurrence frequency, IRI, and mean percent mass of every prey taxon between both sexes of $J$. swinhonis and J. $p$. xanthostoma. Only those prey taxa with IRI greater than 10 were included in the intra- and interspecific comparisons. We applied two indices to measure the extent of diet overlap. The first index quantified the overlap in prey use between two groups (Goodall, 1973):

$$
C_{x y}=1-\frac{1}{2}\left(\sum_{l}^{n}\left|p_{x i}-p_{y i}\right|\right),
$$

where $p_{x i}=x_{i} / X, p_{y i}=y_{i} / Y, n$ was the number of prey taxa used by both groups, $x_{i}$ and $y_{i}$ were the number of individuals of group 1 and group 2 , respectively, using prey taxa $i, X$, and $Y$ were the summation of individuals utilizing prey taxa 1 to prey taxa $n$ by group 1 and group 2, respectively. $C_{x y}$-value ranges from zero (mutually exclusive prey use) to one (completely overlapping prey use).

The second index was the product-moment correlation coefficient (Hurlbert, 1978):

$$
C_{p}=\frac{\left[\sum_{l}^{n}\left(x_{i}-\frac{X}{n}\right)\left(y_{i}-\frac{Y}{n}\right)\right]}{\left[\sum_{l}^{n}\left(x_{i}-\frac{X}{n}\right)^{2} \sum_{l}^{n}\left(y_{i}-\frac{Y}{n}\right)^{2}\right]^{1 / 2}}
$$

where symbols were the same as defined in the previous index. This index measured the correlation of prey use between two groups.

\section{RESUlTS}

Daily activity patterns.-In all hourly intervals, the number of $J$. swinhonis sighted was greater than that of J. p. xanthostoma. However, the distributions of the number of lizards sighted across all hourly intervals from $0700-1800 \mathrm{~h}$ did not differ between the two species (Fig. 1; Chisquare test of homogeneity: $\chi^{2}{ }_{10}=4.09, P>0.9$ ).

Perch habitat.-We recorded perch locations of $235 \mathrm{~J}$. swinhonis and $126 \mathrm{~J}$. p. xanthostoma. Perch locations of the two species intermingled in the study site and were often in close proximity (Fig. 2). Moreover, some trees were perched by both species. The two species did not partition their perch locations in the study site.

Perch height and diameter of J. swinhonis and J. p. xanthostoma are shown in Table 1. Perch height differed significantly both between species and sexes, with significant interactions (Table 2). Pairwise comparisons (Fig. 3A) showed that the significant interaction between species and sex was caused by different intersexual patterns between species. Male J. swinhonis perched significantly higher than females, whereas J. p. xanthostoma exhibited no intersexual difference in perch height. Overall, female J. swinhonis perched much lower than male J. swinhonis and both male and female J. p. xanthostoma, whereas the latter three perched at similar heights.

For perch diameter, the interaction between species and sex was significant (Table 2). Japalura polygonata xanthostoma perched on significantly wider surfaces than J. swinhonis. Pairwise comparisons (Fig. 3B) showed that male J. swinhonis perched on significantly wider surfaces than females, whereas J. p. xanthostoma exhibited no intraspecific difference. Female $J$. 


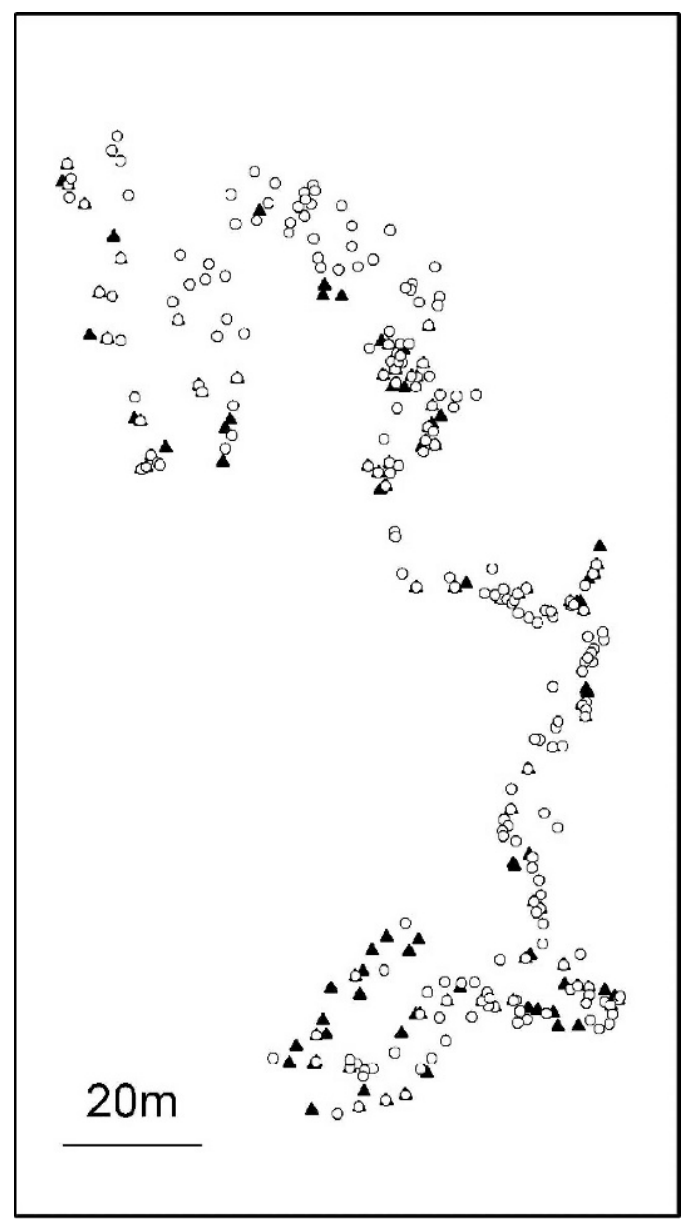

FIG. 2. Distribution of Japalura swinhonis (open circles) Japalura polygonata xanthostoma (filled triangles) in the study site. The topography of the study site rises about $50 \mathrm{~m}$ from lower left to upper right corner of the figure.

swinhonis perched on narrower surfaces than the other groups. Male J. swinhonis used narrower perch surfaces than J. p. xanthostoma females but did not differ from J. p. xanthostoma males.

In summary, the two species differed significantly in both perch height and perch diameter. The differences resulted primarily from the much lower perch height and smaller perch diameter of female J. swinhonis than other groups.

Morphometric analysis.-For all size variables (Table 1), the effects of species, sex, and the interaction terms were highly significant (Table 2). Japalura swinhonis were significantly larger than J. p. xanthostoma, and males were larger than females. Sexual dimorphism in sizes was greater for $J$. swinhonis than for J. $p$. xanthostoma. Male J. swinhonis were significantly larger in all eight size variables $(P<0.05$ in all size variables) than females, which in turn had significantly greater values than both sexes of $J$. p. xanthostoma (Fig. 4A-D). However, male and female J. p. xanthostoma differed only in forelimb lengths $\left(t_{32.2}=2.00, P=0.048 ; P>0.05\right.$ in all other size variables; Fig. $4 \mathrm{~A}-\mathrm{D})$.

Similarly, for most shape variables (Table 1), the effects of species, sex, and the interaction terms were significant (Table 2). Japalura polygonata xanthostoma had relatively greater lengths in FLIMB, and J. swinhonis had relatively greater lengths in HW, HLIMB, and overall SIZE. There was no difference in relative HL. The differences between males and females were contributed by J. swinhonis alone. Male J. swinhonis had relatively larger heads (HW/SIZE: $t_{76.3}=7.57, P$ $<0.0001$; HL/SIZE: $\left.t_{85}=3.70, P=0.0003\right)$, and females had relatively longer limbs (FLIMB/ SIZE: $t_{85}=2.84, P=0.0053$; HLIMB $/$ SIZE: $t_{85}=$ $4.52, P<0.0001)$. Japalura polygonata xanthostoma exhibited no shape dimorphism in any of the shape variables examined. Pairwise comparisons showed that male J. swinhonis had significantly greater values than female J. swinhonis and J. p. xanthostoma in overall size, relative head widths and lengths, and were the shortest in relative forelimb lengths. Female J. swinhonis were the longest in relative hind-limb lengths but were not significantly different from male and female J. p. xanthostoma in HL and FLIMB (Fig. 4E-H).

Diet.-Because the sample size of female J. $p$. xanthostoma stomach content was too small $(N=$ 6) to make meaningful intraspecific comparisons, and intraspecific difference in perch habitat was not detected, we pooled data of both sexes to increase sample size. Occurrence frequency, mean percent mass and IRI of all prey taxa are shown in Table 3. Ants and lepidopteran larvae were the only two prey taxa with considerable importance $(I R I>10)$. High diet overlap was detected in all between-group comparisons (male vs. female J. swinhonis: $C_{x y}=0.88, C_{p}=$ 0.96; male J. swinhonis vs. J. p. xanthostoma: $C_{x y}=$ $0.78, C_{p}=0.92$; female J. swinhonis vs. J. $p$. xanthostoma: $C_{x y}=0.81, C_{p}=0.93$ ).

Occurrence frequency of small-sized prey (ants) did not differ significantly between the three groups $\left(\chi_{2}^{2}=3.79, P>0.1\right)$ nor did that of larger-sized prey (Lepidopteran larvae; $\chi_{2}^{2}=$ $0.45, P>0.75)$. Mean percent mass of ants differed significantly only between $J$. $p$. xanthostoma and female $J$. swinhonis (Wilcoxon $Z$-value $=2.95, P=0.01)$, with the former having greater values. Mean percent mass of Lepidopteran larvae, however, did not differ between the three groups (Kruskal-Wallis test: $\chi^{2}{ }_{2}=1.72$, $P=0.42)$. 
TABLE 2. Results of ANOVAs showing the effects of species, sex, and species-sex interactions. Statistics reported for all size and shape variables are $F_{1.121}$ values; perch height $F_{1,350}$ values; and perch diameter $F_{1,277}$ values.

\begin{tabular}{lccc}
\hline \hline & \multicolumn{3}{c}{ Effects in ANOVA } \\
\cline { 2 - 4 } & Species & Sex & Species $\cdot$ sex \\
\hline Perch habitat & & & \\
Perch height & $9.3^{* *}$ & $18.05^{* * *}$ & $16.73^{* * *}$ \\
Perch diameter & $14.47^{* * *}$ & 0.48 & $4.14^{*}$ \\
Size variables & & & \\
HW & $151.86^{* * *}$ & $68.18^{* * *}$ & $42.04^{* * *}$ \\
HL & $178.44^{* * *}$ & $65.57^{* * *}$ & $38.04^{* * *}$ \\
FLIMB & $232.52^{* * *}$ & $70.91^{* * *}$ & $25.17^{* * *}$ \\
HLIMB & $420.76^{* * *}$ & $43.33^{* * *}$ & $22.94^{* * *}$ \\
Shape variables & & & \\
HW/SIZE & $5.14^{*}$ & $19.41^{* * *}$ & $12.97^{* * *}$ \\
HL/SIZE & $>0.01$ & $5.19^{*}$ & 2.67 \\
FLIMB/SIZE & $11.61^{* * *}$ & 0.39 & $5.68^{*}$ \\
HLIMB/SIZE & $58.12^{* * *}$ & $5.96^{*}$ & $5.48^{*}$ \\
\hline$*$
\end{tabular}

${ }^{*} P<0.05,{ }^{* *} P<0.01,{ }^{* * *} P<0.001$.

Because Lepidopteran larvae were prey of prime importance and relatively large, we tested the possibility that lizards with larger heads consumed larger Lepidopteran larvae. However, mean body diameter of Lepidopteran larvae found in stomachs of the three groups of lizards did not differ (male J. swinhonis: mean $=3.04 \mathrm{~mm}$, $N=12$; female $J$. swinhonis: mean $=2.94 \mathrm{~mm}, N=$ 12; J. p. xanthostoma: mean $=2.22 \mathrm{~mm}, N=11$; Kruskal-Wallis test, $\chi_{2}^{2}=5.51, P=0.06$ ).

\section{DisCUSSION}

The hypothesis that J. swinhonis and J. p. xanthostoma partition resources in time, perch habitat, or diet was only partially supported. First of all, the two species did not temporally divide resources. The two species were active during the same time of year (C-YK, unpubl.

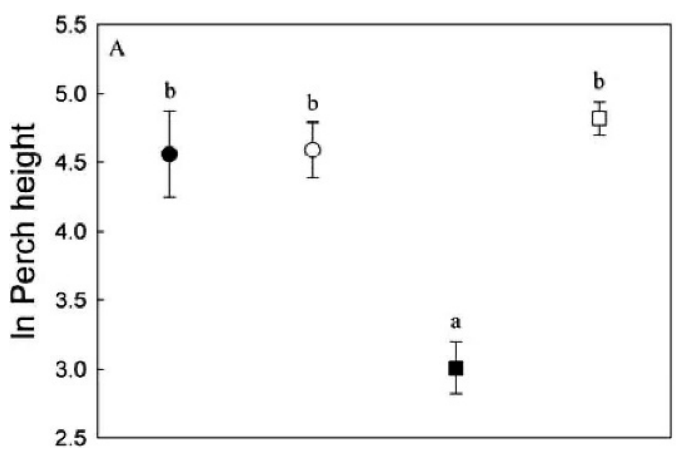

data), and had similar daily activity patterns (Fig. 1). Spatially, the two species used similar macrohabitats. Perch locations of the two species intermingled and were often in close proximity in the woody study site (Fig. 2). Only at a smaller spatial scale did we find female $J$. swinhonis perched at much lower vegetation strata than male J. swinhonis and both sexes of $J$. p. xanthostoma, whereas the latter three perched at similar heights and surfaces (Fig. 3). Finally, we observed extensive overlap in diet composition among all groups. The only discrepancy was that the percent mass of ants consumed by J. p. xanthostoma was twice as high as that by female J. swinhonis. Overall, our results suggested female J. swinhonis partitioned perch habitat from male J. swinhonis and both sexes of J. p. xanthostoma.

Intuitively, one might deduce female $J$. swinhonis that perched lower would perch on wider surface than the other groups. In fact, female J. swinhonis were often found perching not on tall woody plants but on low bushes or in grass. The small surface diameters of low bushes or grass led to the observed small perch diameters by female J. swinhonis. Moreover, female J. swinhonis were the only individuals observed to perch on the ground $(7 / 72$ sightings). The frequency of ground perching was likely underestimated because the cryptic coloration of female lizards blended in well with the understory vegetation. Hence, female $J$. swinhonis did use very different perch habitat from the other groups. Male J. swinhonis and particularly J. p. xanthostoma perched more or less exclusively on tall woody plants. Among them, the group perched on taller heights tended to perch on surfaces with smaller diameters as one would expect (Fig. 3).

Apart from female J. swinhonis, male J. swinhonis and both sexes of J. p. xanthostoma have extensive resource overlaps. They used similar resources in terms of time, perch habitat,

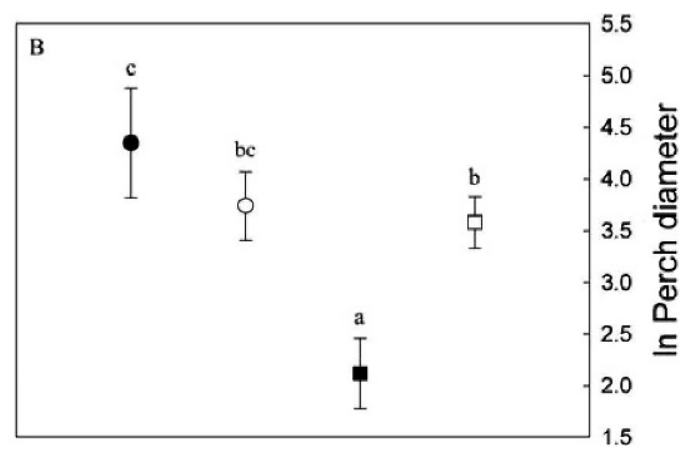

FIG. 3. Perch height (A) and perch diameter (B) of Japalura swinhonis (squares) and Japalura polygonata xanthostoma (circles). Open symbols are males, and filled symbols females. Symbols are mean $\pm 1 \mathrm{SE}$ of $\mathrm{ln}$ transformed values. Groups with the same alphabets do not differ significantly. 

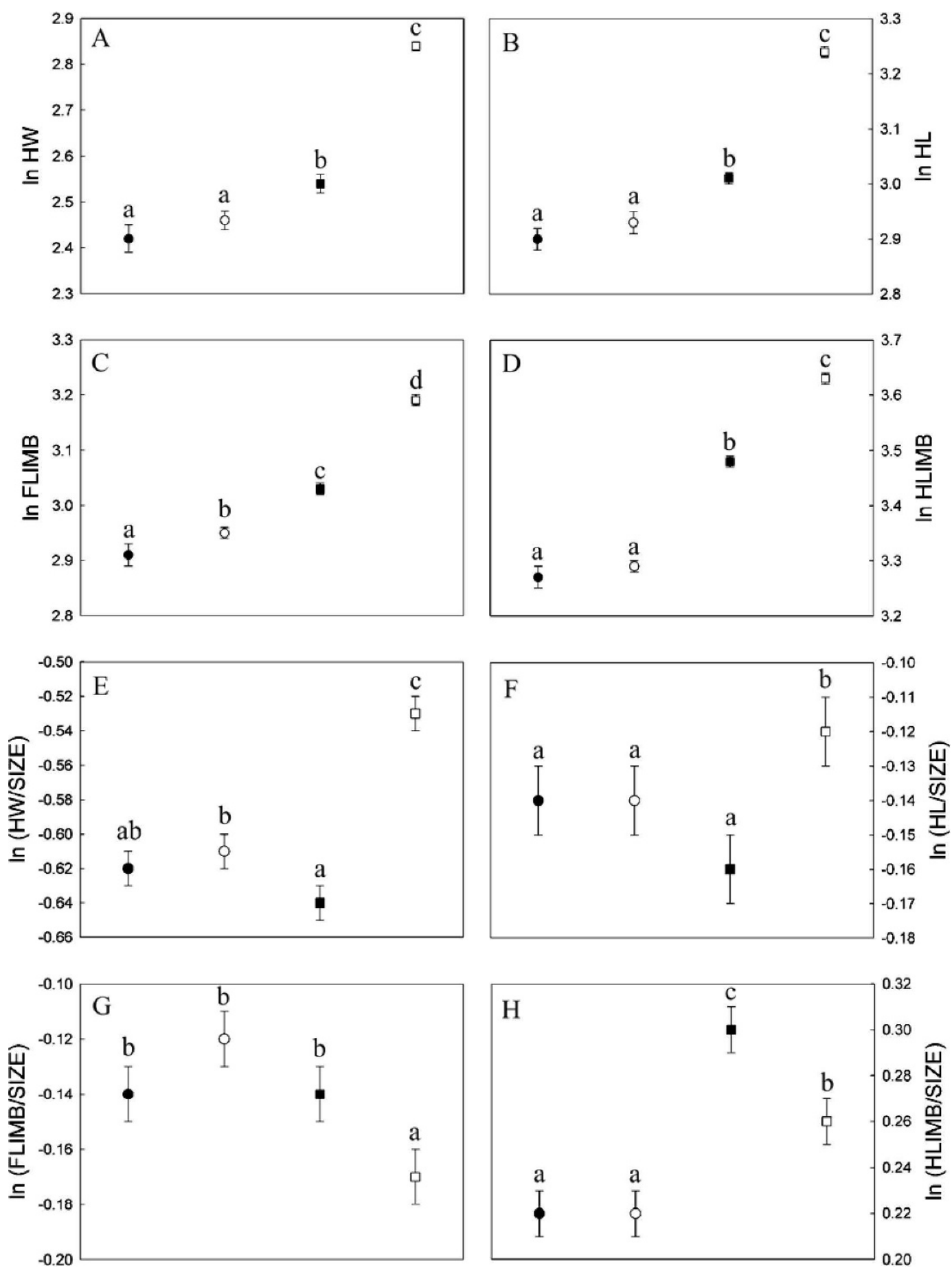

FIG. 4. Means ( $\pm 1 \mathrm{SE})$ of $\ln$-transformed size (A-D) and shape (E-H) variables of Japalura swinhonis (squares) and Japalura polygonata xanthostoma (circles). Open symbols are males, filled symbols females. Groups with the same alphabets do not differ significantly. (A) Head width. (B) Head length. (C) Forelimb length. (D) Hind-limb length. (E) Relative head width. (F) Relative head length. (G) Relative forelimb length. (H) Relative hindlimb length. 
TABLE 3. Occurrence frequency, mean percent weight, and IRI of prey taxa found in stomachs of Japalura swinhonis and Japalura polygonata xanthostoma. Sample sizes of occurrence frequency are 29, 27, and 32 for the three groups, respectively. Sample sizes of mean percent weight are 22 for all groups. Occurrence frequency for this cell is smaller than $1 / 20$. Same with other -

\begin{tabular}{|c|c|c|c|c|c|c|c|c|c|}
\hline \multirow[b]{2}{*}{ Prey taxa } & \multicolumn{3}{|c|}{ Occurrence frequency } & \multicolumn{3}{|c|}{ Mean percent weight } & \multicolumn{3}{|c|}{$I R I$} \\
\hline & Js O & Js $Q$ & Jpx & Js ơ & Js & Jpx & Js O’ & Js & Jpx \\
\hline Class Arachnida & 10 & 15 & 8 & 3.18 & 3.13 & 0.37 & 2.36 & 3.43 & 0.13 \\
\hline Class Diplopoda & 2 & 2 & 2 & 0 & 4.02 & 2.22 & 0 & 0.59 & 0.19 \\
\hline Class Chilopoda & 3 & 3 & 1 & 1.53 & 1.51 & - & 0.34 & 0.33 & - \\
\hline \multicolumn{10}{|l|}{ Class Crustacea } \\
\hline Isopoda & 2 & 5 & 6 & 0.77 & 1.35 & 2.34 & 0.11 & 0.49 & 0.60 \\
\hline Class Gastropoda & 3 & 3 & 2 & 1.30 & 8.06 & 0.16 & 0.29 & 1.77 & 0.01 \\
\hline \multicolumn{10}{|l|}{ Class Insecta } \\
\hline Coleoptera & 6 & 10 & 13 & 5.65 & 7.15 & 7.47 & 2.52 & 5.23 & 4.18 \\
\hline Hemiptera & 5 & 7 & 10 & 6.92 & 5.75 & 2.87 & 2.57 & 2.94 & 1.24 \\
\hline Homoptera & 5 & 4 & 1 & 11.06 & 5.62 & - & 4.11 & 1.64 & - \\
\hline \multicolumn{10}{|l|}{ Hymenoptera } \\
\hline Formicidae & 24 & 25 & 31 & 28.45 & 22.45 & 57.38 & 50.70 & 41.04 & 76.58 \\
\hline Isoptera & 2 & 0 & 0 & 1.80 & - & - & 0.27 & - & - \\
\hline Lepidoptera larvae & 15 & 15 & 15 & 32.17 & 38.55 & 26.32 & 35.83 & 42.29 & 17.00 \\
\hline Orthoptera & 4 & 6 & 2 & 3.04 & 0.54 & 0.86 & 0.90 & 0.24 & 0.07 \\
\hline Psocoptera & 3 & 2 & 0 & 0 & 0 & - & 0 & 0 & - \\
\hline
\end{tabular}

Js: Japalura swinhonis, Jpx: Japalura polygonata xanthostoma.

and diet in our study site. Such results suggested that the two groups could compete strongly. Indeed, male J. swinhonis and male J. p. xanthostoma were observed engaging in antagonistic contests more often than between conspecific males (C-YK, unpubl. data). Since male J. swinhonis were significantly larger than both sexes of J. p. xanthostoma, one would expect the former to perform better in antagonistic encounters and displace the latter. However, such phenomenon was not observed in our study site, and we will explore this issue later in the discussion. There were other possible reasons for the lack of partitioning. For example, predation pressure may have kept lizard population sizes low so that the food base might be unlimited and allowed niche overlap. However, we would not know whether the two species were food limited or were predation limited without food addition or predator removal manipulations.

We had hypothesized that correspondence existed between limb morphology and perch habitat: species with shorter forelimbs would perch on narrower surface. The hypothesis was based on previous observations that species using wide perches have relatively longer limbs and sprint faster but have poorer maneuverability than species using narrow perches (Williams, 1983; Losos, 1990; Irschick and Losos, 1998; Beuttel and Losos, 1999). However, our results showed that the differences in perch habitats could not be consistently attributed to differences in morphology either between or within J. swinhonis and J. p. xanthostoma. Japalura polygonata xanthostoma had relatively shorter hind limbs (Fig. $4 \mathrm{H}$ ) but did not perch on narrower surfaces than J. swinhonis (Fig. 3B). Similarly, male J. swinhonis had relatively shorter hind limbs (Fig. 4H) but did not perch on narrower surface than females (Fig. 3B). The hypothesis of perch width-limb shape correspondence was only supported intraspecifically in J. p. xanthostoma, whose males and females differed neither in perch habitat nor in limb morphology (Figs. 3B, 4C, D).

Similar findings have been reported in other studies investigating overall limb morphology versus habitat use (Beuttel and Losos, 1999; Vanhooydonck and Van Damme, 1999; Schulte et al., 2004; Irschick et al., 2005a,b). Habitat homogeneity has been suggested to be responsible for the lack of correlation between habitat use and limb morphology in Liolaemus (Schulte et al., 2004) and lacertid lizards (Vanhooydonck and Van Damme, 1999). If the functional demands placed by habitats on different species were similar, differences in perch diameter would not serve as a selective pressure for the differentiation of limb morphology between species. In our study, lizards mostly perched on tree trunks, and the range of perch diameters used may be broad for all individuals compared to lizards' body lengths (mean perch diameter was greater than mean body length). Thus, the coexistence of the two species could not be explained by a trade-off in the efficiencies of using perches of different widths. 
Nevertheless, trade-offs in habitat use efficiency may exist in ways other than we have originally hypothesized. The use of vertical perches by male J. swinhonis and J. p. xanthostoma involved a biomechanical challenge. Vanhooydonck and Van Damme (1999) pointed out that organisms moving on vertical surfaces should keep their centers of mass close to the substrate in order to move efficiently. Accordingly, lizards with relatively larger heads would be at a disadvantage in moving on vertical surfaces because their centers of mass were further away from the substrates (Herrel et al., 2002). However, they could compensate for this by keeping their heads close to the substrate while moving (Vanhooydonck and Van Damme, 1999; Zaaf et al., 1999). In accord with this model, we observed that male J. swinhonis, which had relatively larger heads (high HW/ SIZE and HL/SIZE values), had relatively shorter forelimbs (low FLIMB/SIZE values) than J. p. xanthostoma (Tables 1, 2). On vertical surfaces, the latter, being smaller in head size, should have an advantage over male J. swinhonis in moving around. Thus, we suggest that there may be a trade-off between fighting ability and maneuverability that could allow coexistence. Although male J. swinhonis, being larger, may have better fighting ability, J. p. xanthostoma could maneuver around tree trunks and branches to search for prey and avoid fighting more easily.

In addition to the biomechanical trade-offs mentioned above, there were other possible reasons that may act in synergy to account for the morphological differentiation of the two species. One such possibility was that limb morphology was correlated with certain ecological features other than perch habitat. For example, it had been shown in Liolaemus lizards that morphology was correlated with escape behaviors but not habitat structures (Schulte et al., 2004): species with longer trunks, wider bodies, and a narrow pelvis tended to move longer distances from predators. Furthermore, relatively long hind limbs have been shown to provide better jumping ability in 15 Caribbean Anolis species (Losos, 1990) and different age/ sex classes of a green anole (Anolis carolinensis) population (Irschick et al., 2005b). Jumping, initiated by hind limbs, is a common response in Japalura lizards to approaching observers and presumably, predators (C-YK, pers. obs.). Since both male and particularly female J. swinhonis have relatively longer hind limbs than J. p. xanthostoma, we suspected that J. swinhonis may be more likely to use jumping as an antipredator strategy. Particularly, the long hind limbs of female J. swinhonis may have been selected to escape predators on the ground.
An interesting observation emerging from our study was that male and female J. swinhonis used different perch habitats, which has also been reported in another J. swinhonis population (Lin and Lu, 1982). Lin and Lu (1982) suggested that the differential habitat use could be explained in the context of sexual selection in males and natural selection in females. Indeed, males of the sexually dimorphic J. swinhonis may gain from advertising from higher perches to attract potential mates and discourage conspecific males even with a cost from the biomechanical perspective. In contrast, females, with cryptic body coloration, may gain by perching near the ground especially during pregnancy when locomotion is retarded by eggs and if the low vegetation offered more food and protection. More information is needed to validate our hypothesis. Although most Japalura lizards perched on surfaces $>120 \mathrm{~cm}$ off ground, we were not sure whether high perches were better habitat than lower perches. In the study area, low vegetation was more structurally complex and likely had higher food availability and lower predation risk than higher vegetation. Yet, only female J. swinhonis frequently used low vegetation. Further investigation is required to quantify the quality of low versus high vegetation for Japalura lizards. It is interesting that the two species did not cooccur in Lin and Liu (1982) as well. Thus, J. swinhonis females staying close to the ground was not a product of interspecific interaction with J. p. xanthostoma.

Finally, we had hypothesized that a correspondence would exist between head morphology and diet: species with larger heads would consume larger or tougher prey (Forsman and Lindell, 1993; Preest, 1994; Verwaijen et al., 2002; Vincent et al., 2004). The hypothesis was not supported. Japalura swinhonis had larger heads but did not consume bulkier prey items, such as beetles or Lepidopteran larvae, than J. $p$. xanthostoma. Extensive feeding niche overlap was detected between any two of the three groups. The absence of correspondence between head size and diet could be explained by the fact that, during our study period, even the bulkiest prey consumed by lizards were relatively small compared to lizards' gape size. As a consequence, differences in head size could not contribute to dietary differentiation because prey could be easily handled regardless of head size. Although a possibility exists that differences in head sizes contribute to dietary differentiation outside the study period, we argue that it is unlikely because the number of lizards declined steeply to $<1 / 10$ of the summer population size after August (C-YK, unpubl. data). Competition for food, if it exists, 
would lessen. Moreover, J. swinhonis enter hibernation from November to February (Lin and $\mathrm{Lu} \mathrm{1982),} \mathrm{and} \mathrm{J.} \mathrm{p.} \mathrm{xanthostoma} \mathrm{also}$ disappeared in the field around November (CYK, pers. obs.). Therefore, food competition outside study period, even if it exists, should be of little importance for the evolution or maintenance of different head sizes.

Nonetheless, the greater absolute and relative head size of males than females might be a consequence of intrasexual selection for fighting ability in J. swinhonis, as has been suggested in many lizard taxa (reviewed in Andersson, 1994). Jaws are involved in the antagonistic behaviors between males in territorial disputes (Wei and Lin, 1981). Greater relative head width and head length provided more space for muscle attachment and granted stronger biting force (C-YK, pers. obs.) and better fighting ability. Although the correlation between head size and reproductive success has not been established, we suggest that differences in head morphology were the consequence of male-male competition. Japalura polygonata xanthostoma, on the contrary, did not exhibit sexual dimorphism in head size. Although we have observed biting involved in male-male antagonistic behaviors, head size may not be the main target of sexual selection in this species. Other traits, such as the crimson throats, may be more relevant.

In conclusion, we have described resource use both intra- and interspecifically for J. swinhonis and J. p. xanthostoma, and demonstrated differences in perch habitat and diet between the two species. However, the partitioning of resources was either incomplete (e.g., male J. swinhonis did not partition from J. p. xanthostoma in perch habitat) or slight (e.g., mass of ants in diet). However, the trade-off between fighting ability and maneuverability on narrow surfaces may allow for the coexistence of male J. swinhonis and J. p. xanthostoma. Alternatively, the two species may have partitioned additional resource dimensions that we did not measure, or there may be no competition in the first place. Moreover, other mechanisms such as high resource availability and differential vulnerability to predation or disturbance could have minimized competitive exclusion too. Many questions emerged from our study. Our study served as a pioneer work for future studies to fully clarify the ecological relationship between the two species.

Acknowledgments.-This study would not have been possible without the assistance of the following people: M.-H. Chen, R.-J. Chen, J. Kao, Y.-T. Jeng, and Y.-J. Kuo. We thank K.-Y. Lue for comments on experimental procedures and S.-F. Shao for the help in identifying insect items. Special acknowledgments go to L.-L. Lee for stimulating a thorough reorganization of early drafts and B. Stein for providing invaluable insights to manuscript writing. Finally, we thank H.-C. Lin of Taipei City Zoo for the permission to conduct the study in the zoo.

\section{Literature Cited}

Andersson, M. 1994. Sexual Selection. Princeton University Press, Princeton, NJ.

BeutTel, K., AND J. B. Losos. 1999. Ecological morphology of Caribbean anoles. Herpetological Monographs 13:1-28.

Bjorndal, K. A., A. B. Bolten, C. J. Lagueux, and D. R. JACKSON. 1997. Dietary overlap in three sympatric congeneric freshwater turtles (Pseudemys) in Florida. Chelonian Conservation and Biology 2:430-433.

Butler, M. A., AND J. B. Losos. 2002. Multivariate sexual dimorphism, sexual selection, and adaptation in Greater Antillean-lizards. Ecological Monographs 72:541-559.

Forsman, A., AND L. E. Lindell. 1993. The advantage of a big head: swallowing performance in adders, Vipera berus. Functional Ecology 7:183-189.

Goodall, D. W. 1973. Sample similarity and species correlation. In R. H. Whittaker (ed.), Ordination and Classification of Communities, pp. 106-156. Junk, The Hague, The Netherlands.

Grant, P. R. 1986. Ecology and Evolution of Darwin's Finches. Princeton University Press, Princeton, NJ.

Herrel, A., J. Meyers, and B. Vanhooydonck. 2002. Relations between microhabitat use and limb shape in phrynosomatid lizards. Biological Journal of the Linnean Society 77:149-163.

Hurlbert, S. H. 1978. The measurement of niche overlap and some relatives. Ecology 59:67-77.

Hutchinson, G. E. 1957. Concluding remarks. Cold Spring Harbor Symposium of Quantitative Biology 22:415-427.

IRSCHICK, D. J., AND J. B. Losos. 1998. A comparative analysis of the ecological significance of maximal locomotor performance in Caribbean Anolis lizards. Evolution 52:219-226.

Irschick, D. J., E. Carlisle, J. Elstrott, M. Ramos, C. Buckley, B. Vanhooydonck, J. Meyers, and A. Herrel. 2005a. A comparison of habitat use, morphology, clinging performance and escape behavior among two divergent green anole lizards (Anolis carolinensis) populations. Biological Journal of the Linnean Society 85:223-234.

Irschick, D. J., B. VAnHOOYdonck, A. Herrel, AND J. MEYERS. 2005b. Intraspecific correlations among morphology, performance and habitat use within a green anole lizard (Anolis carolinensis) populations. Biological Journal of the Linnean Society 85:211-221.

JIAN, R.-C. 1990. Morphological Variations of External Structures of Genus Japalura in Taiwan. Unpubl. master's thesis. Tunghai University, Taichung, Taiwan, Republic of China.

Kohlsdorf, T., T. J. Garland, And C. A. Navas. 2001. Limb and tail lengths in relation to substrate usage in Tropidurus lizards. Journal of Morphology 248:151-164. 
LIN, J.-Y., AND H.-Y. Cheng. 1986. Annual reproductive and lipid storage patterns of the Agamid lizard, Japalura swinhonis mitsukurii in southern Taiwan. Bulletin of the Institute of Zoology, Academia Sinica 25:13-23.

LIN, J.-Y., AND K.-H. Lu. 1982. Population ecology of the lizard Japalura swinhonis formosensis (Sauria: Agamidae) in Taiwan. Copeia 1982:425-434.

Losos, J. B. 1990. Ecomorphology, performance capability, and scaling of West Indian Anolis lizards: an evolutionary analysis. Ecological Monographs 60:369-388.

1994. Integrative approaches to evolutionary ecology: Anolis lizards as model systems. Annual Review of Ecology and Systematics 25:467-493.

Melville, J., AND R. SwaIN. 2000. Evolutionary relationships between morphology, performance and habitat openness in the lizard genus Niveoscincus (Scincidae: Lygosominae). Biological Journal of the Linnean Society 70:667-683.

Mosimann, J. 1970. Size allometry: size and shape variables with characterizations of the lognormal and generalized gamma distributions. Journal of the American Statistical Association 65:930-945.

Preest, M. R. 1994. Sexual size dimorphism and feeding energetics in Anolis carolinensis: why do females take smaller prey than males? Journal of Herpetology 28:292-298.

Schluter, D., and P. R. Grant. 1984. Determinants of morphological patterns in communities of Darwin's finches. American Naturalist 123:175-196.

Schulte, J. A. I., J. B. Losos, F. B. Cruz, and H. NúÑez. 2004. The relationship between morphology, escape behaviour and microhabitat occupation in the lizard clade Liolaemus (Iguanidae:Tropidurinae: Liolaemini). Journal of Evolutionary Biology 17:408-420.
SHAN, G. 2001. Natural Portraits of Lizards in Taiwan. Big Tree Culture Enterprise Co., Ltd, Taipei.

VANHOOYDONCK, B., AND R. VAN DAMmE. 1999. Evolutionary relationships between body shape and habitat use in lacertid lizard. Evolutionary Ecology Research 1:785-805.

Verwaijen, D., R. Van Damme, and A. Herrel. 2002. Relationships between head size, bite force, prey handling efficiency and diet in two sympatric lacertid lizards. Functional Ecology 16:842-850.

Vincent, S. E., A. Herrel, and D. J. Irschick. 2004. Ontogeny of intersexual head shape and prey selection in the pitviper Agkistrodon piscivorus. Biological Journal of the Linnean Society 81: 151-159.

WALKER, J. A. 1997. Ecological morphology of lacustrine Threespine Stickleback Gasterosteus aculeatus L (Gasterosteidae) body shape. Biological Journal of the Linnean Society 61:3-50.

WeI, S.-Y., AND J.-Y. LIN. 1981. Behavioral study of Japalura swinhonis formosensis (Sauria: Agamidae). Tunghai Journal of Biology 22:33-48.

Williams, E. E. 1972. The origin of faunas. Evolution of lizard congeners in a complex island fauna: a trial analysis. Evolutionary Biology 6:47-89.

1983. Ecomorphs, faunas, island size, and diverse end points in island radiations of Anolis. In R. B. Huey, E. R. Pianka, and T. W. Schoener (eds.), Lizard Ecology: Studies of a Model Organism, pp. 326-370. Harvard University Press, Cambridge, MA.

Zaha, A., A. Herrel, P. Aerts, and F. De Vree. 1999. Morphology of the appendicular musculature in geckos with different locomotor habits (Lepidosauria). Zoomorphology 119:9-22.

Accepted: 18 June 2007. 